Iranian Journal of Pathology | ISSN: 2345-3656

\title{
Association of Sulfur Mustard-induced Ocular Problems with Serum and Blood Biochemical Parameters Changes
}

\author{
HassanGhasemi ${ }^{1,2}$, Nayere Askari ${ }^{3}$, Mohammad Mehdi Naghizadeh ${ }^{4}$, Susan Kabudanian Ardestani ${ }^{5}$, Sakine \\ Moaiedmohseni $^{1}$, Mohammad Reza Vaez Mahdavi', Tooba Ghazanfari ${ }^{1}$ " \\ Immunoregulation Research Center, Shahed University, Tehran, Iran \\ Dept.of Ophthalmology, Shahed University, Tehran, Iran \\ Dept.of biology, Faculty of Basic Sciences, Shahid Bahonar University, Kerman, Iran \\ Dept. of Biostatistics, Fasa University of Medical Science, Fasa, Fars Province, Iran \\ Institute of Biochemistry and Biophysics, Tehran University, Tehran, Iran
}

\begin{tabular}{c}
\hline KEYWORDS \\
\hline Mustard Gas; \\
Ocular Surface; \\
Serum Biochemical \\
Parameters; \\
Blood Biochemical Parameters
\end{tabular}

\section{Article Info}

Received 25 Oct 2016;

Accepted 05 Feb 2017;

Published Online 17 July 2018;

\section{ABSTRACT}

Background \& objective: Many biochemical features of sulfur mustard (SM) intoxication remained unknown. So far, the direct association between biochemical parameter changes and ocular problems in patients exposed to SM is not evaluated.The current study aimed at evaluating the associations between the ocular findings in patients with SM intoxication and the changes of serum and blood biochemical parameters.

Methods: In the current study, 372 patients exposed to SM and 128 matched controls were compared concerning the association between their ocular problems and biochemical parameters. Ocular problems include photophobia, ocular surface discomfort (OSD), etc. Biochemical parameters include uric acid, creatinine ( $\mathrm{Cr})$, hematocrit $(\mathrm{HCT})$, total, direct and indirect bilirubin, high-density lipoproteins (HDL), alanine aminotransferase (ALT), calcium (Ca), fasting blood sugar (FBS), mean corpuscular hemoglobin concentration (MCHC), etc.

Results: The SM-exposed group with photophobia, OSD, tearing, blurred vision, abnormal tear status, and slit-lamp findings had significantly higher mean serum and blood levels of uric acid, Cr, HCT, and total and indirect bilirubin than the controls. The SM-exposed group with photophobia, tearing, ocular pain, blurred vision, bulbar conjunctival and limbal abnormalities had significantly higher mean serum and blood levels of HDL, ALT, Ca, FBS, MCHC, and HDL, indirect and total bilirubin, compared to the control group.

Conclusion: The association of photophobia with uric acid, OSD and tearing with $\mathrm{Cr}$, photophobia with HDL, ocular pain with $\mathrm{Ca}$, and blurred vision with FBS may be explained for their known ocular effects in the SM-exposed subjects. SM-induced biochemical changes may intensify the ocular problems induced by the direct effects of SM.

Copyright (C) 2018, IRANIAN JOURNAL OF PATHOLOGY. This is an open-access article distributed under the terms of the Creative Commons Attribution-noncommercial 4.0 International License which permits copy and redistribute the material just in noncommercial usages, provided the original work is properly cited.

\section{Introduction}

Current chemical weapons are the nerve agents (sarin, tabun, VX, cyclosarin, and soman), the vesicant or blister agents (eg, sulfur mustard), choking agents (phosgene and chlorine), incapacitating agents (fentanyls and adamsite), riot control agents (mace and pepper spray), blood agents (cyanide), and toxic industrial chemical agents (formaldehyde, hydrofluoric acid, and ammonia) (1). Sulfur mustard (SM) is the most famous vesicant agent used since World War I and still in huge amounts is stored elsewhere in the world. Due to high diffusion in nearly all tissue, there is no organ to remain intact during severe intoxication with SM (2). Lungs, eyes, and skin are amongst the most important organs involved during exposure. SM causes respiratory system damages (chronic obstructive lung disease and lung fibrosis), eye lesions (recurrent corneal ulceration, chronic conjunctivitis, 
and dry eye), skin lesions (blisters, abnormal pigmentation, and cancer), bone marrow depression, and cancers (3). Apparent clinical features of SM intoxication- especially in eyes- lungs and skin are recognized in animal and human from many years ago(4-6). Cytotoxic effects of SM lead to disruption of normal cellular functions and diffused metabolic abnormalities such as enzymatic deficiencies, mitotic and cell division abnormalities, bone marrow depression, and hematopoietic disturbances. In fact, SM disrupts cellular activities through binding to amino acids, amines, and proteins (7). Apart from SM, there were few papers in the literature on the association of serum and blood biochemical changes and ocular problems. Recently, many papers shed light on some hidden biochemical and immunological aspects of SMintoxication. Some of these papers are especially focused on direct association between the involvement of major organs and immune system (8-13). Also, there are some studies indicating changes of serum and blood biochemical parameters induced by SM, such as blood uric acid and serum creatinine $(14,15)$, serum transaminases and alkaline phosphatases (16), lipid profile (17), and blood sugar (18). But, none of them evaluated the direct association between biochemical parameter changes with ocular problems in the patients exposed to SM. Still, many biochemical features of SM intoxication are unknown.

Regardless of the rationales that seem ambiguous in many occasions, the current study aimed at evaluating the associations between ocular findings in patients with SM intoxication and their serum and blood biochemical parameter changes.

\section{Materials and methods}

\section{Study design and participant}

The current study was a part of Sardasht-Iran Cohort Study (SICS) (19). The participants were 372 documented patients exposed to SM as cases and 128 non-exposed controls matched with the cases. All participants underwent a thorough ocular history taking, and examination and evaluation of serum and blood biochemical parameters. Presence of any ocular symptoms such as photophobia, ocular surface dis- comfort (burning, itching, and redness), foreign body sensation, tearing, blurred vision, pain, and dry eye sensation were recorded. The conditions of lids, tear meniscus, bulbar conjunctiva, limbal tissue, cornea, and anterior segment were evaluated using a slit-lamp biomicroscopy (Nidek, Gamagori, Japan).

\section{Ethical considerations}

The study was approved by the Ethical Committee of Board of Research Ethics of Janbazan Medical and Engineering Research Center (JMERC), the Board of Research of the Ministry of Health and Medical Education and Shahed University, Tehran, Iran. Written informed consent was obtained from all participants ultimately selected for the study inclusion.

\section{Blood sampling}

After completion of the clinical examination, $10-\mathrm{mL}$ blood samples were taken from the brachial vein of fasting subjects in the case and control groups. Blood samples were collected into the sterile tubes containing anticoagulant agent [ethylenediaminetetraacetic acid (EDTA)] for the evaluation of hematological parameters and non-anticoagulant tubes for biochemical tests. Blood samples in non-anticoagulant tubes were centrifuged at $3000 \mathrm{rpm}$ for 5 minutes and serum samples were harvested and kept at $-70^{\circ} \mathrm{C}$ until testing.

\section{Biochemical parameters evaluation}

Serum and blood biochemical parameters including urea, creatinine $(\mathrm{Cr})$, uric acid, cholesterol, triglyceride (TG), low-density lipoprotein (LDL), intermediate-density lipoproteins (IDL), high-density lipoproteins (HDL), calcium (Ca), phosphorous $(\mathrm{P})$, total and direct bilirubin, alanine aminotransferase (ALT) or serum glutamic pyruvic transaminase (SGPT), enzyme aspartate aminotransferase (AST) or serum glutamic oxaloacetic transaminase (SGOT), and alkaline phosphatase (ALP) were determined using commercially available kits from Pars Azmoon (Tehran, Iran). Serum samples were analyzed with a BT 3000 Plus biochemical analyzer (Biotecnica, Italy). The BT 3000 analyzer is a commercial colorimetric assay kit using the spectrophotometric method. 


\section{Determination of the hematological param- eters}

The complete blood count (CBC) was performed with a hematology cell counter (Sysmex KX-21, Japan). Routine hematological parameters were determined including red blood cell count (RBC), platelet count (PLT), hemoglobin content $(\mathrm{Hb})$, hematocrit (HCT), red cell distribution width (RDW), mean corpuscular hemoglobin $(\mathrm{MCH})$, mean corpuscular volume (MCV), mean corpuscular hemoglobin concentration (MCHC), and mean platelet volume (MPV).

\section{Statistical analysis}

Statistical analysis was performed by the Mann-
Whitney and Spearman rank correlation tests using SPSS version 16. The median values of the first and third quartiles (Q1, Q3) were selected. The differences were considered significant at $\mathrm{P}$ value $\leq 0.05$.

\section{Results}

Orderly, participants exposed to SM with photophobia, ocular surface discomfort (OSD) (burning, itching, and redness), tearing, blurred vision, abnormal tear status, and any findings on slit-lamp examination had significantly higher mean serum and blood levels of uric acid, $\mathrm{Cr}, \mathrm{HCT}$, total bilirubin, and indirect bilirubin than the controls $(\mathrm{P}=0.035,<0.0001,0.003$, $0.003,0.034,0.031$, respectively) (tables $1-3$ ).

Table 1. Association of Ocular Symptoms and Blood/Serum Biochemical Parameters

\begin{tabular}{|c|c|c|c|c|c|c|c|c|c|c|c|c|c|}
\hline & \multicolumn{6}{|c|}{ Control } & \multicolumn{6}{|c|}{ Exposed } & \multirow[b]{2}{*}{ P-value ${ }^{b}$} \\
\hline & $\mathbf{N}$ & Mean & SD & Median & Q1 & Q3 & $\mathbf{N}$ & Mean & SD & Median & Q1 & Q3 & \\
\hline \multicolumn{14}{|c|}{ Uric Acid } \\
\hline \multicolumn{14}{|c|}{ Photophobia } \\
\hline No & 102 & 5.745 & 1.153 & 5.8 & 5 & 6.4 & 238 & 5.887 & 1.159 & 5.8 & 5.1 & 6.6 & 0.301 \\
\hline Yes & 26 & 5.431 & 0.863 & 5.55 & 5 & 6 & 135 & 5.934 & 1.140 & 5.85 & 5.1 & 6.5 & 0.035 \\
\hline P-value ${ }^{a}$ & \multicolumn{6}{|c|}{0.197} & \multicolumn{6}{|c|}{0.705} & \\
\hline \multicolumn{14}{|c|}{ Creatinine } \\
\hline \multicolumn{14}{|c|}{ Ocular discomfort } \\
\hline No & 103 & 1.038 & 0.263 & 1 & 0.9 & 1.1 & 264 & 1.078 & 0.174 & 1.1 & 1 & 1.2 & 0.091 \\
\hline Yes & 25 & 0.972 & 0.131 & 1 & 0.9 & 1 & 109 & 1.098 & 0.159 & 1.1 & 1 & 1.2 & $0.001>$ \\
\hline P-value & \multicolumn{6}{|c|}{0.226} & \multicolumn{6}{|c|}{0.302} & \\
\hline \multicolumn{14}{|l|}{ Tearing } \\
\hline No & 95 & 1.035 & 0.273 & 1 & 0.9 & 1.1 & 246 & 1.078 & 0.166 & 1.1 & 1 & 1.2 & 0.078 \\
\hline Yes & 33 & 0.997 & 0.123 & 1 & 0.9 & 1.1 & 127 & 1.096 & 0.177 & 1.1 & 1 & 1.2 & 0.003 \\
\hline P-value ${ }^{a}$ & \multicolumn{6}{|c|}{0.442} & \multicolumn{6}{|c|}{0.333} & \\
\hline \multicolumn{14}{|c|}{ Calcium } \\
\hline \multicolumn{14}{|l|}{ Eye pain } \\
\hline No & 114 & 10.05 & 0.77 & 9.9 & 9.5 & 10.5 & 343 & 9.79 & 0.53 & 9.8 & 9.5 & 10.1 & $0.001>$ \\
\hline Yes & 14 & 9.91 & 0.6 & 9.85 & 9.5 & 10.5 & 30 & 10.07 & 0.76 & 10.1 & 9.5 & 10.5 & 0.493 \\
\hline P-value ${ }^{a}$ & \multicolumn{6}{|c|}{0.513} & \multicolumn{6}{|c|}{0.008} & \\
\hline \multicolumn{14}{|c|}{ FBS, mg\% } \\
\hline \multicolumn{14}{|c|}{ Blurring of vision } \\
\hline No & 80 & 94.95 & 22.65 & 88.00 & 84.00 & 98.00 & 214 & 93.11 & 17.93 & 90.00 & 84.0 & 97.0 & 0.468 \\
\hline Yes & 48 & 92.30 & 17.14 & 90.00 & 84.00 & 95.00 & 159 & 100.15 & 29.90 & 93.00 & 86.0 & 103 & 0.084 \\
\hline P-value ${ }^{a}$ & \multicolumn{6}{|c|}{0.486} & \multicolumn{6}{|c|}{0.005} & \\
\hline
\end{tabular}


Table 2. Association of Ocular Symptoms and Some Blood/Serum Biochemical Parameters

\begin{tabular}{|c|c|c|c|c|c|c|c|c|c|c|c|c|c|}
\hline & & \multicolumn{5}{|c|}{ Control } & \multicolumn{6}{|c|}{ Case } & \multirow[b]{2}{*}{ P-value ${ }^{b}$} \\
\hline & $\mathbf{N}$ & Mean & SD & Median & Q1 & Q3 & $\mathbf{N}$ & Mean & SD & Median & Q1 & Q3 & \\
\hline \multicolumn{14}{|c|}{ HDL } \\
\hline \multicolumn{14}{|c|}{ Photophobia } \\
\hline No & 102 & 26.78 & 9.66 & 25 & 20 & 35 & 238 & 28.35 & 10.53 & 27 & 21 & 36 & 0.198 \\
\hline Yes & 26 & 30.96 & 11.62 & 31 & 22 & 38 & 135 & 31.11 & 11.9 & 30 & 22 & 39 & 0.953 \\
\hline P-value & \multicolumn{6}{|c|}{0.061} & \multicolumn{6}{|c|}{0.021} & \\
\hline \multicolumn{14}{|c|}{ Bulbar conjunctiva } \\
\hline Normal & 126 & 27.74 & 10.3 & 26 & 20 & 36 & 337 & 28.85 & 10.43 & 28 & 21 & 36 & 0.307 \\
\hline Abnormal & 2 & 24.5 & 0.71 & 24.5 & 24 & 25 & 36 & 33.89 & 15.43 & 31 & 23 & 47 & --- \\
\hline P-value ${ }^{a}$ & \multicolumn{6}{|c|}{--- } & \multicolumn{6}{|c|}{0.009} & \\
\hline \multicolumn{14}{|c|}{ HCT } \\
\hline \multicolumn{14}{|c|}{ Blurring of vision } \\
\hline No & 80 & 44.6 & 3.4 & 44.7 & 42.3 & 46.3 & 214 & 44.9 & 3.1 & 44.9 & 43.1 & 47 & 0.473 \\
\hline Yes & 48 & 43.3 & 4 & 43.7 & 41.6 & 46.3 & 159 & 45.2 & 3.7 & 45.3 & 43.2 & 47.5 & 0.003 \\
\hline P-value ${ }^{a}$ & \multicolumn{6}{|c|}{0.052} & \multicolumn{6}{|c|}{0.396} & \\
\hline \multicolumn{14}{|c|}{ МСНC } \\
\hline \multicolumn{14}{|c|}{ Bulbar conjunctiva } \\
\hline Normal & 126 & 35.6 & 1.4 & 35.7 & 34.8 & 36.4 & 337 & 35.2 & 1.3 & 35.2 & 34.5 & 36 & 0.004 \\
\hline Abnormal & 2 & 35.7 & 0.2 & 35.7 & 35.5 & 35.8 & 36 & 35.8 & 1.5 & 35.8 & 34.9 & 36.3 & --- \\
\hline P-value ${ }^{a}$ & \multicolumn{6}{|c|}{--- } & \multicolumn{6}{|c|}{0.010} & \\
\hline
\end{tabular}

Table 3. Association of Ocular Symptoms and Some Blood/ Serum Biochemical Parameters

\begin{tabular}{|c|c|c|c|c|c|c|c|c|c|c|c|c|c|}
\hline & \multicolumn{6}{|c|}{ Control } & \multicolumn{6}{|c|}{ Case } & \multirow[b]{2}{*}{ P-value } \\
\hline & $\mathbf{N}$ & Mean & SD & Median & Q1 & Q3 & $\mathbf{N}$ & Mean & SD & Median & Q1 & Q3 & \\
\hline \multicolumn{14}{|c|}{ Total Bilirubin } \\
\hline \multicolumn{14}{|c|}{ Tear status } \\
\hline Normal & 117 & 0.9 & 0.4 & 0.8 & 0.7 & 1.1 & 321 & 0.9 & 0.4 & 0.8 & 0.7 & 1 & 1.000 \\
\hline Abnormal & 11 & 0.8 & 0.1 & 0.8 & 0.7 & 0.8 & 52 & 1 & 0.3 & 0.9 & 0.8 & 1.2 & 0.034 \\
\hline P-value & \multicolumn{6}{|c|}{0.412} & \multicolumn{6}{|c|}{0.085} & \\
\hline \multicolumn{14}{|c|}{ Limbal tissue } \\
\hline Normal & 128 & 0.7 & 0.34 & 0.6 & 0.5 & 0.8 & 362 & 0.7 & 0.29 & 0.6 & 0.5 & 0.8 & 1.000 \\
\hline Abnormal & 0 & --- & --- & --- & --- & --- & 11 & 0.91 & 0.36 & 0.85 & 0.6 & 1.2 & --- \\
\hline P-value ${ }^{a}$ & \multicolumn{6}{|c|}{---} & \multicolumn{6}{|c|}{0.019} & \\
\hline \multicolumn{14}{|c|}{ Indirect Bilirubin } \\
\hline \multicolumn{14}{|c|}{ Any findings in slit-lamp } \\
\hline No & 113 & 0.72 & 0.35 & 0.6 & 0.5 & 0.8 & 292 & 0.7 & 0.3 & 0.6 & 0.5 & 0.8 & 0.567 \\
\hline Yes & 15 & 0.54 & 0.17 & 0.55 & 0.4 & 0.6 & 81 & 0.71 & 0.29 & 0.7 & 0.5 & 0.8 & 0.031 \\
\hline P-value ${ }^{a}$ & \multicolumn{6}{|c|}{0.053} & \multicolumn{6}{|c|}{0.789} & \\
\hline \multicolumn{14}{|c|}{ Limbal tissue } \\
\hline Normal & 128 & 0.7 & 0.34 & 0.6 & 0.5 & 0.8 & 362 & 0.7 & 0.29 & 0.6 & 0.5 & 0.8 & 1.000 \\
\hline Abnormal & 0 & --- & --- & --- & --- & --- & 11 & 0.91 & 0.36 & 0.85 & 0.6 & 1.2 & --- \\
\hline
\end{tabular}


161. Association of Sulfur Mustard-induced ...

\begin{tabular}{|c|c|c|c|c|c|c|c|c|c|c|c|c|c|}
\hline P-value & \multicolumn{6}{|c|}{--- } & \multicolumn{6}{|c|}{0.019} & \\
\hline \multicolumn{14}{|c|}{ ALT } \\
\hline \multicolumn{3}{|c|}{ Tearing } & & & & & & & & & & & \\
\hline No & 95 & 21 & 8 & 20 & 16 & 25 & 246 & 20 & 6 & 19 & 16 & 22 & 0.212 \\
\hline Yes & 33 & 22 & 6 & 20 & 18 & 27 & 127 & 23 & 11 & 20 & 16 & 26 & 0.616 \\
\hline P-value ${ }^{a}$ & \multicolumn{6}{|c|}{0.513} & \multicolumn{6}{|c|}{$0.001>$} & \\
\hline
\end{tabular}

Patients exposed to SM developing photophobia had significantly higher mean serum levels of uric acid than the matched controls $(P=0.035)$. Patients exposed to SM with ocular discomfort had significantly higher mean serum levels of creatinine than the matched controls $(P<0.001)$. Patients exposed to SMdeveloping tearing had significantly higher mean serum levels of creatinine than the matched controls $(P=0.003)$. Despite significantly lower mean serum levels of calcium in the subjects exposed to SM without ocular pain than the matched controls, the subjects exposed to SM with ocular pain had significantly higher mean serum levels of calcium than the matched subjects exposed to SM without ocular pain ( $P=0.008$ ). Patients exposed to SMdeveloping blurred vision had significantly higher mean serum levels of FBS than the matched subjects exposed to SM without blurred vision $(P=0.005)$.

P-valuea: Comparison between each group (the Mann-Whitney test)

P-valueb: Comparison between the control and SMexposed subjects of each group (the Mann-Whitney test)

FBS, Fasting blood sugar

Patients exposed to SMdeveloping blurring of vision had significantly higher mean serum levels of HCT than the matched controls $(P=0.003)$. Patients exposed to SMwith photophobia had significantly higher mean serum levels of HDL than the matched subjects who exposed to SM without photophobia $(P=0.021)$. Patients exposed to SM developing bulbar conjunctival abnormality had significantly higher mean blood levels of MCHC than the matched subjects exposed to SM without bulbar conjunctival abnormality $(P=0.010)$. Patients exposed to SMdeveloping bulbar conjunctival abnormality had significantly higher mean serum levels of HDL than the matched subjects exposed to SM without bulbar conjunctival abnormality $(P=0.009)$.

P-value ${ }^{\text {a: }}$ Comparison between each group (the Mann-Whitney test)

P-value ${ }^{\mathrm{b}}$ : Comparison between the control and SMexposed subjects of each group (the Mann-Whitney test)

- HCT, Hematocrit

- HDL, High-density lipoproteins

- MCHC, Mean corpuscular hemoglobin concentration

- HDL, High-density lipoprotein

Participants exposed to SMwith abnormal tear status had significantly higher mean serum levels of total bilirubin than the matched controls $(P=0.034)$. Patients exposed to SM with any findings in slit-lamp had significantly higher mean serum levels of indirect bilirubin than the matched controls $(P=0.031)$. Patients exposed to SMdeveloping tearing had significantly higher mean serum levels of ALT than the matched subjects exposed to SM without tearing $(P<0.001)$. Patients exposed to SMdeveloping limbal tissue abnormality had significantly higher mean serum levels of indirect bilirubin than the matched subjects exposed to SM without limbal tissue abnormality $(P=0.019)$.

Patients exposed to SMwith limbal tissue abnormality had significantly higher mean serum levels of total bilirubin than the matched subjects exposed to SM without limbal tissue abnormality $(P=0.015)$.

P-valuea: Comparison between each group (the Mann-Whitney test)

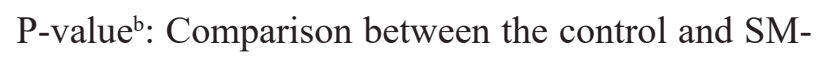
exposed subjects of each group (the Mann-Whitney test)

ALT, Alanine aminotransferase 
Also, Patients exposed to SMwith photophobia, tearing, ocular pain, blurred vision, bulbar conjunctival abnormalities, and limbal tissue abnormalities had significantly higher mean serum levels of HDL, ALT, Ca, FBS, MCHC, and HDL, indirect and total bilirubin compared with the subjects exposed to SM without such abnormalities $(P=0.021,<0.0001$, $0.008,0.005,0.010$, and $0.009,0.019$, and 0.015 , respectively) (tables 1-3). The biochemical parameter changes including blood uric acid, Cr, HCT, total bilirubin, and indirect bilirubin were significantly different between the SM-exposed subjects with ocular problems and the matched controls. On the other hand, the tables 1-3 indicate that the biochemical parameter changes including HDL, ALT, Ca, FBS, $\mathrm{MCHC}, \mathrm{HDL}$, and indirect and total bilirubin were significantly different between the cases exposed to SM developing with some ocular problems and the SM-exposed ones without the same ocular problems.

\section{Discussion}

The findings of the current study showed that patients exposed to SMwith photophobia, OSD, tearing, blurred vision, abnormal tear status, and any slit-lamp findings had significantly higher mean serum and blood levels of uric acid, Cr, HCT, total bilirubin, and indirect bilirubin than the matched controls. On the other hand, subjects exposed to SM with photophobia, tearing, ocular pain, blurred vision, bulbar conjunctival abnormality, and limbal tissue abnormalities had significantly higher mean serum and blood levels of HDL, ALT, Ca, FBS, MCHC, and indirect and total bilirubin than the matched subjects exposed to SM without such findings.

Patients exposed to SMdeveloping bulbar conjunctival abnormality had significantly higher mean serum levels of HDL than the matched subjects exposed to SM without bulbar conjunctival abnormality.

HDL level in the patients exposed to SMwith photophobia was significantly higher than the SM-exposed subjects without photophobia. Increased serum level of HDL in the subjects exposed to SM developing photophobia may be due to its protective role, but this increase was not enough to protect against this prob- lem. Thus, some other mechanisms may be involved. In the current study, the mean serum HDL level in both groups were lower than the normal range of HDL, which can be due to genetic, nutritional, and geographic reasons and their lifestyle.

Patients exposed to SMwith abnormal tear status had significantly higher mean serum levels of total bilirubin than the matched controls. This difference could not be attributed to exposure to SM, because there was no difference between the SM-exposed subjects and the controls with normal tear status. It may be due to other unknown SM-induced mechanisms. Patients exposed to SM with abnormal tear status and limbal tissue abnormality, respectively, had significantly higher mean serum levels of total bilirubin and indirect bilirubin than their matched SM-exposed subjects without these abnormalities. Bilirubin is an endogenous antioxidant (20) and can suppress inflammation in the vasculature (21). Yasuda et al., showed that the increase in serum bilirubin levels may have a protective role against diabetic retinopathy in persons with either diabetes or impaired glucose metabolism, independent of known risk factors for diabetic retinopathy (22). Therefore, in the current study, the elevated level of bilirubin in the SM-exposed subjects with limbal tissue abnormalities may have a protective effect, but the level was not enough to protect against the abnormality; hence, other mechanisms may be involved. Topically applied SM in guinea pig liver was hepatotoxic and caused severe steatosis and a significant rise in SGOT/AST and glutamic pyruvate transaminase SGPT/ALT levels that reached the maximum 3 days after application. Partial recovery was achieved on the day 6 (23). Dermal application of SM in mice caused an increase in serum transaminases and ALP (16). Amongst liver function tests, total serum bilirubin (but not direct bilirubin, SGOT, SGPT, and ALP) was significantly higher in hospitalized vs. non-hospitalized SM-exposed patients (24). In the current study, the SM-exposed patients with tearing had significantly higher levels of serum ALT than the SM-exposed ones without such complication. This was consistent with the findings of the current study in patients exposed to SM with tearing, 
compared with the SM-exposed group without such problem.

Although, associations between ocular findings and serum and blood biochemical alterations in SMexposed humans are not yet reported in the literature that makes comparative studies difficult; there are some studies on serum and blood biochemical alterations in humans and animals exposed to SM, regardless of their ocular problems.

Cutaneous and pulmonary exposures to high concentration of SM in mice significantly increased circulatory blood uric acid and serum creatinine $(14,15)$. Also, there are few studies on the association of some serum and blood biochemical alterations (eg, $\mathrm{Ca}$ and uric acid) and OSD under pathologic conditions other than SM exposure. Long-term elevation in serum uric acid caused deposition of uric acid crystals on ocular surface and induced ocular surface discomfort such as photophobia $(25,26)$. It was consistent with the current study findings on comparing the SM-exposed andcontrol subjectswith photophobia, which can be attributed to the local effects of SM or systemic effects of uric acid on ocular surface.

Balali mood et al., reported significantly higher levels of HCT after SM exposure in 40 male patients within the age range of 16 to 20 years; this level and the levels of $\mathrm{Hb}$ were significantly correlated with the severity of respiratory complications (27). In another study, total counts for RBC and MCV (but not $\mathrm{MCH}$ and $\mathrm{MCHC}$ ) were significantly higher in cases with more severe intoxication $(28,29)$. Seven days after percutaneous administration of $2 \times$ LD50 of SM, a significant weight-loss and increase in $\mathrm{RBC}$ and $\mathrm{Hb}$ were observed in mice (30). In the SM-exposed human, the mean number of RBCs and Hb levels were not significantly different, compared with those of the controls, but increased during the 5-year follow-up. This might be related to chronicpulmonary disorders (31). Also in the present study, the SM-exposedsubjects with blurred vision had significantly higher levels of HCT than the matched controls. On the other hand, the SM-exposed subjects with bulbar conjunctival abnormalities had significantly higher levels of
MCHC than the matched subjects exposed to SM without such abnormality.

A single dermal application of $1.0 \times$ LD50 of SM in mice caused a significant hyperglycemia 24 hours after the application. Liver glycogen content decreased; while brain, muscles, and kidney glycogen contents did not change (18). In parallel, the SM-exposed subjects with blurred vision had significantly higher mean blood levels of FBS than the matched subjects exposed to SM without such problem. In the experimental dogs, significant lipid profile changes were observed in the alpha-fraction, which gradually shifted to the beta-fraction of lipoproteins, appeared up to 24 hours after exposure to SM (17). It was consistent with the current study findings in the SM-exposed subjectswith photophobia and bulbar conjunctival abnormalities, compared with the ones exposed to SM without such abnormalities.

The majority of studies indicated the effects of SM on local or intracellular $\mathrm{Ca}$ deposition or changes not on the serum Ca levels (32-35). Association of band keratopathy with the elevation of serum $\mathrm{Ca}$ and creatinine was suggested in some studies other than SM exposure (33). In chronic renal failure, increase in serum Ca-Pi products may induce red irritated eyes (36). In such patients, a band-shaped keratopathy and photophobia developed, in addition to the limbal and conjunctival calcification, mostly secondary to an induced tertiary hyperparathyroidism (37). In the current study, despite significantly lower mean serum levels of $\mathrm{Ca}$ in the $\mathrm{SM}$-exposed subjects without ocular pain than their matched controls; those SMexposed subjects with ocular pain had significantly higher mean serum levels of Ca than the SM-exposed subjects without such abnormality.

In conclusion, SM-induced biochemical parameter alterations, especially in serum and blood uric acid, $\mathrm{Cr}$, HDL, Ca, and FBS, may additionally intensify the direct effects of SM on ocular tissues and increase ocular problems such as photophobia, OSD, tearing, ocular pain, and blurred vision. However, the rationales for associations between other ocular problems and biochemical changes may seem inexplicable in 
the SM-exposed patients; more investigations are needed.

\section{Acknowledgements}

The current study was carried out by the Immunoregulation Research Center of Shahed University and Janbazan Medical and Engineering Research Center (JMERC), Tehran, Iran. Authors would like to thank all the participants for their cooperation with the study.

\section{Funding/Support}

The research was supported financially by the Iranian Foundation of Martyr and Veterans Affairs and Ministry of Health and Medical Education, Tehran, Iran.

\section{Conflict of interests}

The authors declared no conflict of interest.

\section{References}

1. Anderson PD. Emergency management of chemical weapons injuries. J Pharm Pract. 2012;25(1):61-8. https://doi. org/10.1177/0897190011420677 PMID:22080590

2. Drasch G, Kretschmer E, Kauert G, Von Meyer L. Concentrations of mustard gas [bis (2-chloroethyl) sulfide] in the tissues of a victim of a vesicant exposure. J Forensic Sci. 1987;32(6):1788-93. $\quad$ https://doi.org/10.1520/ JFS11235J PMID: $\underline{3430139}$

3. Kehe K, Szinicz L. Medical aspects of sulphur mustard poisoning. Toxicology. 2005;214(3):198-209. https://doi.org/10.1016/j. tox.2005.06.014 PMID: 16084004

4. Aasted A, Darre E, Wulf HC. Mustard gas: clinical, toxicological, and mutagenic aspects based on modern experience. Ann Plast Surg. 1987;19(4):330-3. https://doi.org/10.1097/00000637-198710000$\underline{00007}$ PMID: $\underline{318637}$

5. Leipner N, Dewes W, Schüller H, Helm U. [Lung parenchymatous changes following mustard gas poisoning]. RoFo. 1987;147(2):152-5. https:// doi.org/10.1055/s-2008-1048611 PMID:2819968

6. Minden H, Zschunke E. [Extensive skin dam- age caused by mustard gas]. Dtsch Gesundheitsw. 1958;13(14):426-8. PMID:13547738

7. Dacre JC, Goldman M. Toxicology and pharmacology of the chemical warfare agent sulfur mustard. Pharmacol Rev. 1996;48(2):289-326. PMID: $\underline{804107}$

8. Ghazanfari T, Mostafaie A, Yaraee R, Pourfarzam S, Faghihzadeh S, Rezaei A, et al. Are serum levels of immunoglobulin classes and $\mathrm{IgG}$ subclasses involved in delayed pulmonary complications induced by sulfur mustard? SardashtIran Cohort Study. Int Immunopharmacol. 2013;17(3):936-43. https://doi.org/10.1016/j.intimp.2012.12.028 PMID:23395986

9. Pourfarzam S, Yaraee R, Hassan ZM, Yarmohammadi ME, Faghihzadeh S, Soroush M-R, et al. Chemokines, MMP-9 and PMN elastase in spontaneous sputum of sulfur mustard exposed civilians: Sardasht-Iran Cohort Study. Int Immunopharmacol. 2013;17(3):958-63. https://doi. org/10.1016/j.intimp.2012.12.015 PMID:23370297

10. Ghasemi H, Yaraee R, Hassan ZM, Faghihzadeh S, Soroush M-R, Pourfarzam S, et al. Association of ophthalmic complications in patients with sulfur mustard induced mild ocular complications and serum soluble adhesion molecules: Sardasht-Iran Cohort Study. Int Immunopharmacol. 2013;17(3):980-5. https://doi. org/10.1016/j.intimp.2012.12.014 PMID:23370300

11. Ghasemi H, Mostafaie A, Yaraee R, Hassan ZM, Rezaei A, Mahmoudi M, et al. Association of serum immunoglobulins levels and eye injuries in sulfur mustard exposed: SardashtIran Cohort Study. Int Immunopharmacol. 2013;17(3):944-51. https://doi.org/10.1016/j.intimp.2012.12.027 PMID:23370295

12. Panahi Y, Davoudi SM, Beiraghdar F, Saadat A, Sahebkar A. Relationship between levels of IFN $\gamma, \mathrm{TNF} \alpha$, and TGF $\beta$ and pruritus in sulfur mustard-exposed veterans. J Immunotoxicol. 2013;10(2):173-7. https://doi.org/10.3109/15476 $\underline{\text { 91X.2012.707697 }}$ PMID:22994697

13. Yaraee R, Hassan ZM, Pourfarzam S, Rezaei A, Faghihzadeh S, Ebtekar M, et al. Fibrinogen and inflammatory cytokines in spontaneous sputum of sulfur-mustard-exposed civilians-SardashtIran Cohort Study. Int Immunopharmacol. 
165. Association of Sulfur Mustard-induced ...

2013;17(3):968-73. https://doi.org/10.1016/j.intimp.2012.12.024 PMID:23375935

14. Kumar O, Vijayaraghavan R. Effect of sulphur mustard inhalation exposure on some urinary variables in mice. J Appl Toxicol. 1998;18(4):257-9. $\quad$ https://doi.org/10.1002/ (SICI) 1099-1263(199807/08)18:4<257::AIDJAT $501>3.0 . \mathrm{CO} ; 2-4$

15. Kumar O, Sugendran K, Vijayaraghavan R. Protective effect of various antioxidants on the toxicity of sulphur mustard administered to mice by inhalation or percutaneous routes. Chem Biol Interact. 2001;134(1):1-12. https:// doi.org/10.1016/S0009-2797(00)00209-X

16. Sharma M, Vijayaraghavan R, Agrawal OP. Comparative toxic effect of nitrogen mustards (HN-1, HN-2, and HN-3) and sulfur mustard on hematological and biochemical variables and their protection by DRDE-07 and its analogues. Int J Toxicol. 2010;29(4):391-401. https://doi. org/10.1177/1091581810365730 PMID:20466873

17. Hrusovský J. [Electrophoretic determination of lipoproteins in the blood of dogs after the administration of beta, beta'-dichlorodiethylsulfide]. Vet Med (Praha). 1979;24(12):745-9.

18. Sugendran K, Jeevaratnam K, Husain K, Singh R, Srivastava D. Effects of topically applied sulphur mustard on tissue glycogen, blood glucose, lactate and pyruvate in mice. Indian J Physiol Pharmacol. 1992;36:219-21. PMID: 1473858

19. Ghazanfari T, Faghihzadeh S, Aragizadeh H, Soroush MR, Yaraee R, Mohammad Hassan Z, et al. Sardasht-Iran cohort study of chemical warfare victims: design and methods. Arch Iran Med. 2009;12(1):5-14. PMID:19111023

20. Klaver CC, Wolfs RC, Vingerling JR, Hofman A, de Jong PT. Age-specific prevalence and causes of blindness and visual impairment in an older population: the Rotterdam Study. Arch Ophthalmol. 1998;116(5):653-8. https://doi. org/10.1001/archopht.116.5.653 PMID:9596502

21. Troughton JA, Woodside JV, Young IS, Arveiler $\mathrm{D}$, Amouyel $\mathrm{P}$, Ferrières $\mathrm{J}$, et al. Bilirubin and coronary heart disease risk in the Prospective Epidemiological Study of Myocardial Infarction (PRIME). Eur J Cardiovasc Prev Rehabil.
2007;14(1):79-84. https://doi.org/10.1097/01.hjr. $\underline{0000230097.81202 .9 \mathrm{f}} \quad$ PMID:17301631

22. Yasuda M, Kiyohara Y, Wang JJ, Arakawa S, Yonemoto K, Doi Y, et al. High serum bilirubin levels and diabetic retinopathy: the Hisayama Study. Ophthalmology. 2011;118(7):1423-8. https://doi.org/10.1016/j.ophtha.2010.12.009

23. Chauhan R, Murty L. Effect of topically applied sulphur mustard on guinea pig liver. J Appl Toxicol. 1997;17(6):415-9. https://doi.org/10.1002/

(SICI) 1099-1263(199711/12)17:6<415::AIDJAT465>3.0.CO;2-D

24. Ghasemi H, Ghazanfari T, Ghassemi-Broumand M, Javadi MA, Babaei M, Soroush MR, et al. Long-term ocular consequences of sulfur mustard in seriously eye-injured war veterans. $\mathrm{Cu}-$ tan Ocul Toxicol. 2009;28(2):71-7. https://doi. org/10.1080/15569520902913936 PMID: $\underline{19514930}$

25. Lin J, Zhao G-Q, Che C-Y, Yang S-S, Wang Q, Li C-G. Characteristics of ocular abnormalities in gout patients. Int J Ophthalmol. 2013;6(3):307. PMID:23826523 PMCID:PMC3693010

26. Sarma P, Das D, Deka P, Deka AC. Subconjunctival urate crystals: a case report. Cornea. 2010;29(7):830-2. PMID:20489594

27. Balali-Mood M, Hefazi M, Mahmoudi M, Jalali E, Attaran D, Maleki M, et al. Long-term complications of sulphur mustard poisoning in severely intoxicated Iranian veterans. Fundam Clin Pharmacol. 2005;19(6):713-21. https://doi.org/10.1111/j.1472-8206.2005.00364.x PMID: 16313284

28. Nadoushan MRJ, Ghazanfari T, Yaraee R, Mahdavi MRV, Soroush MR, Moaiedmohseni $\mathrm{S}$, et al. Total serum bilirubinemia and intensity of sulfur mustard exposure in Iranian chemical victims 20 years after exposure. Toxin Rev. 2009;28(1):44-7. https://doi. org/10.1080/15569540802689865

29. Hefazi M, Maleki M, Mahmoudi M, Tabatabaee A, Balali-Mood M. Delayed complications of sulfur mustard poisoning in the skin and the immune system of Iranian veterans 16-20 years after exposure. Int J Dermatol. 2006;45(9):1025-31. https://doi.org/10.1111/ j.1365-4632.2006.03020.x PMID: 16961503 
30. Gautam A, Vijayaraghavan R. Prophylactic effect of gossypin against percutaneously administered sulfur mustard. Biomed Environ Sci. 2007;20(3):250-9. PMID: 17672217

31. Ghanei M. Delayed haematological complications of mustard gas. J Appl Toxicol. 2004;24(6):493-5. https://doi.org/10.1002/ jat.1006 PMID: 15558826

32. Ham H-Y, Hong C-W, Lee S-N, Kwon M-S, Kim Y-J, Song D-K. Sulfur mustard primes human neutrophils for increased degranulation and stimulates cytokine release via TRPM2/ p38 MAPK signaling. Toxicol Appl Pharmacol. 2012;258(1):82-8. https://doi.org/10.1016/j. $\underline{\text { taap.2011.10.010 }}$ PMID:22036725

33. Kim Y-B, Lee Y-S, Choi D-S, Cha S-H, Sok D-E. Inactivation of microsomal $\mathrm{Ca} 2+-\mathrm{ATPase}$ by 2-chloroethylethyl sulfide. Chem Biol Interact. 1995;97(3):239-46. https://doi.org/10.1016/0009-

\section{7(95)03619-W}

34. Shin S, Choi D-S, Kim Y-B, Cha S-H, Sok D-E. The release of lysosomal arylsulfatase from liver lysosomes exposed to 2-chloroethylethyl sulfide. Chem Biol Interact. 1995;97(3):22938. https://doi.org/10.1016/0009-2797(95)03618-V

35. Braun M, Jonas J. Band-like corneal degeneration as the initial sign of sarcoidosis. Klin Monbl Augenheilkd. 1996;209(5):328-9. https://doi. org/10.1055/s-2008-1035329 PMID:여년

36. Mullaem G, Rosner MH, editors. Ocular Problems in the Patient with End-Stage Renal Disease. Seminars in dialysis; 2012: Wiley Online Library. PMID:22686705

37. Klaassen-Broekema $\mathrm{N}$, Van Bijsterveld $\mathrm{O}$. Limbal and corneal calcification in patients with chronic renal failure. Br J Ophthalmol. 1993;77(9):569-71. $\quad$ https://doi.org/10.1136/ bjo.77.9.569 PMID: $\underline{8218054}$

\section{How to Cite This Article}

Ghasemi H, Askari N, Naghizadeh M, Kabudanian Ardestani S, Moaiedmohseni S, Vaez Mahdavi M, Ghazanfari T. Association of Sulfur Mustard-induced Ocular Problems with Serum and Blood Biochemical Parameters Changes.

Iranian Journal of Pathology, 2018; 13(2): 157-166. 